\title{
Design of Fast Real Time Controller for the SSSC Based on Takagi-Sugeno (TS) Adaptive Neuro-Fuzzy Control System
}

\author{
Mohammed Y. Suliman ${ }^{1}$, M. E. Farrag BEng, MSc, PhD, MIET, MIEEE, FHEA ${ }^{2}$ and Sinan Bashi ${ }^{1}$ \\ ${ }^{1}$ Department of Electrical Engineering,University of Mosul,Iraq \\ Phone number:+00964 7704116100, e-mail: m_yahya1973@yahoo.com, sinanbashi@hotmail.com \\ ${ }^{2}$ School of Engineering \& Built Environment, Glasgow Caledonian University \\ 70 Cowcaddens Rd,Glasgow, G4 0BA, Glasgow, UK \\ Phone number: +44 (0) 75953293 55, e-mail: mohamed.farrag@gcu.ac.uk
}

\begin{abstract}
FACTS (Flexible AC Transmission Systems) technology is one aspect of the power electronics revolution that is taking place in all areas of electric energy. The power transfer capability of a transmission line can be enhanced by using power electronics based system like FACTS that offer high speed and reliable control capability. The Static Synchronous Series Compensator (SSSC) is the second generation of the FACTS controller, which is used to control the power flow in the transmission line. In this paper, a new scheme to control SSSC using adaptive neuro fuzzy logic is proposed, in this controller, Takagi-Sugeno fuzzy rules are trained using off-line neuro fuzzy system, also, instantaneous power theory is used to calculate the power system parameters due to its high accuracy and less computation. The simulation and practical results show that real time application of the proposed controller is possible and robust compared to conventional controllers previously investigated. The experiment results obtained using the dSPACE data acquisition system and Matlab real time toolbox.
\end{abstract}

\section{Key words}

SSSC, Instantaneous Power Theory, Fuzzy Logic.

\section{Introduction}

Increased use of transmission facilities owing to higher industrial demand and deregulation of the power supply industry has provided the necessity for exploring new ways of maximizing the power transfers of existing transmission facilities, while maintaining acceptable levels of system reliability and stability $[1,2]$. In such an environment, applications of the Flexible AC Transmission Systems (FACTS) in power systems have a significant impact on the power system stability and reliability. The FACTS facilitates power flow control, increased power transfer capability, and enhances the security and stability of power systems without expanding transmission and generation utilities. Static Synchronous Series Compensation (SSSC) is one of the series connected FACTS devices that capable of enhancing the power flow in the transmission corridor.
Different control algorithms have been applied to control the injected voltage of the SSSC. Conventional PI controller is proposed to control the device based on the d-q reference frame [3]. It is well known that the fixed gain PI controller cannot perform satisfactorily over a wide range of power system operating conditions. In recent years, new artificial intelligence-based approaches have been proposed to design a FACTS-based supplementary damping controller. These approaches include particle swarm optimization [4, 5], genetic algorithm [6], differential evolution [7], multi-objective evolutionary algorithm [8]. However, the computation time and consequently its suitability for real time applications are the main concern for most of these control techniques.

Artificial neural networks (ANN) methodology has captured the interest in a large number of applications as well as electrical power engineering. The applications include, but not limited to, economical load dispatching and power system stabilizers and controllers. The results have shown that ANNs have great potential in improving power system online and off-line applications [9].

The fuzzy logic control has been applied successfully in power system computer simulation [10], it does not require a detailed mathematical model of the controlled system. The intensive computation time and the huge data memory required are the limit factors of implementing real time fuzzy controllers with large number of control rules. The first type fuzzy logic controllers (using Mamdani membership functions) may not be able to provide a wide variation of control gains for the SSSC to perform robustly at different compensation levels. Alternatively, a second type, based on Takagi-Sugeno (TS), fuzzy controller can provide a wide range of control gain variation and also can use either linear / non-linear consequent expressions of the fuzzy rule base, the coefficients of the consequents are system dependent and have not been systematically chosen [11].

The purpose of this paper is to design SSSC based of TS fuzzy controller in order to regulate the power flow in a transmission line. The controller's rules are optimised- 
using Adaptive Neuro-Fuzzy Inference System (ANFIS). The fuzzy rules are trained using gradient descent and least squares estimate for tuning every rule antecedent and consequent, respectively. The proposed controller has small computation time compared to classical fuzzy controllers, thereby it is implemented in real time using SIMULINK and dSPACE ds1103 data acquisition system. The simulation and experimental results highlight the effectiveness of the adaptive TS fuzzy controller in optimising the SSSC performance. In order to obtain fast responses, the instantaneous power theory for active and reactive measurements was used to calculate the active and reactive power flow in the system that needed to be controlled.

\section{SSSC Model and Control}

Static synchronous series compensator is a series compensator of the FACTS family. It injects an almost sinusoidal voltage (based on switching frequency and inverter configuration) with variable amplitude. It is equivalent to an inductive or a capacitive reactance in series with the transmission line. The heart of SSSC is a Voltage Source Inverter (VSI) that is supplied from a DC storage capacitor. With no external DC link, the injected voltage has two parts: the main part is in quadrature with the line current and emulates an inductive or capacitive reactance in series with the transmission line. The less significant part is in phase with the line current to supply the inverter losses. When the injected voltage is lagging the line current, it will emulate a capacitive reactance in series with the line, causing the line current as well as power flow through the line to increase. When the injected voltage is leading the line current, it will emulate an inductive reactance in series with the line, causing the line current as well as power flow through the line to decrease. SSSC is superior to other FACTS series-connected devices and the benefits of using SSSC are:

- Elimination of bulky passive components capacitors and reactors.

- Symmetric capability in both inductive and capacitive operating modes.

- Possibility of connecting an energy source on the $\mathrm{DC}$ side to exchange real power with the AC network.

An SSSC comprises a voltage source inverter and a coupling transformer that is used to insert the ac output voltage of the inverter in series with the transmission line. The magnitude and phase of this inserted ac compensating voltage can be rapidly adjusted by the SSSC controls.

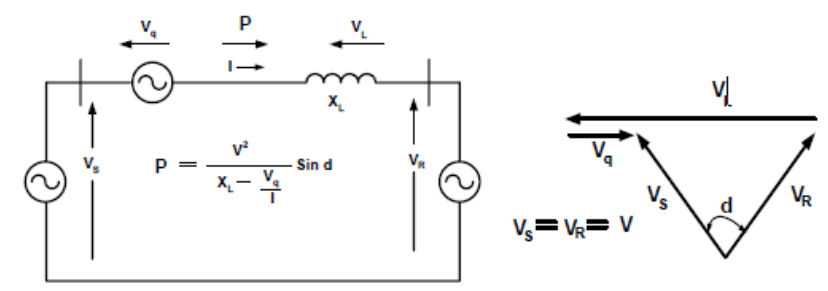

Fig. 1 Elementary two-machine system with an SSSC and the associated phasor diagram
The SSSC injects the compensating voltage in series with the line irrespective of the line current magnitude. The transmitted power $\left(\mathrm{p}_{\mathrm{q}}\right)$, therefore becomes a parametric function of the injected voltage, and can be expressed as follows:

$$
p_{q}=\frac{W^{2}}{\partial} \sin \delta+\frac{\psi}{\partial} V_{q} \cos \left(\frac{\delta}{2}\right)
$$

The SSSC, therefore can increase the transmittable power, and also decrease it, simply by reversing the polarity of the injected ac voltage. The reversed $\left(180^{\circ}\right.$ phase-shifted) voltage adds directly to the reactive voltage drop of the line as if the reactive line impedance was increased. Furthermore, if the injected voltage is made larger than the voltage impressed across the uncompensated line by the sending- and receiving end systems, that is if $|\mathrm{Vq}|>\mid \mathrm{V} 1$ $\mathrm{V} 2$ |, then the power flow can reverse. Apart from the stable operation of the system with both positive and negative power flows, it can also be observed that the SSSC has an excellent (sub-cycle) response time and that the transition from positive to negative power flow through zero voltage injection is perfectly smooth and continuous [12].

\section{Application of Instantaneous Power Theory}

For fast measuring active and reactive power, instantaneous power theory was used. The p-q theory, or "Instantaneous Power Theory", was developed by Akagi et al in 1983, with the objective to apply for controlling active power filters [13]. This theory is based on timeDomain, what makes it valid for operation in steady-state or transitory regime, as well as for generic voltage and current power system waveforms, allowing to control the active power filters in real-time. Another important characteristic of this theory is the simplicity of the calculations, which involves only algebraic calculation exception to the need of separating the mean and alternated values of the calculated power component. The $p-q$ theory performs a transformation known as "Clarke Transformation" of a stationary reference system of coordinates a-b-c to $\alpha-\beta-0$ coordinates [14].

$$
\begin{aligned}
& {\left[\begin{array}{l}
u_{0} \\
u_{\alpha} \\
u_{\beta}
\end{array}\right]=\sqrt{\frac{2}{3}}\left[\begin{array}{ccc}
\frac{1}{\sqrt{2}} & \frac{1}{\sqrt{2}} & \frac{1}{\sqrt{2}} \\
1 & -\frac{1}{2} & -\frac{1}{2} \\
0 & \frac{\sqrt{3}}{2} & -\frac{\sqrt{3}}{2}
\end{array}\right]\left[\begin{array}{l}
u_{1} \\
u_{2} \\
u_{3}
\end{array}\right]} \\
& {\left[\begin{array}{l}
i_{0} \\
i_{\alpha} \\
i_{\beta}
\end{array}\right]=\sqrt{\frac{2}{3}}\left[\begin{array}{ccc}
\frac{1}{\sqrt{2}} & \frac{1}{\sqrt{2}} & \frac{1}{\sqrt{2}} \\
1 & -\frac{1}{2} & -\frac{1}{2} \\
0 & \frac{\sqrt{3}}{2} & \frac{-\sqrt{3}}{2}
\end{array}\right]\left[\begin{array}{l}
i_{1} \\
i_{2} \\
i_{3}
\end{array}\right]}
\end{aligned}
$$

Then the active and reactive power compensated calculated by:

$$
\left[\begin{array}{l}
p \\
q
\end{array}\right]=\left[\begin{array}{cc}
v_{\alpha} & v_{\beta} \\
v_{\beta} & -v_{\alpha}
\end{array}\right]\left[\begin{array}{l}
i_{S \alpha} \\
i_{S \beta}
\end{array}\right]
$$




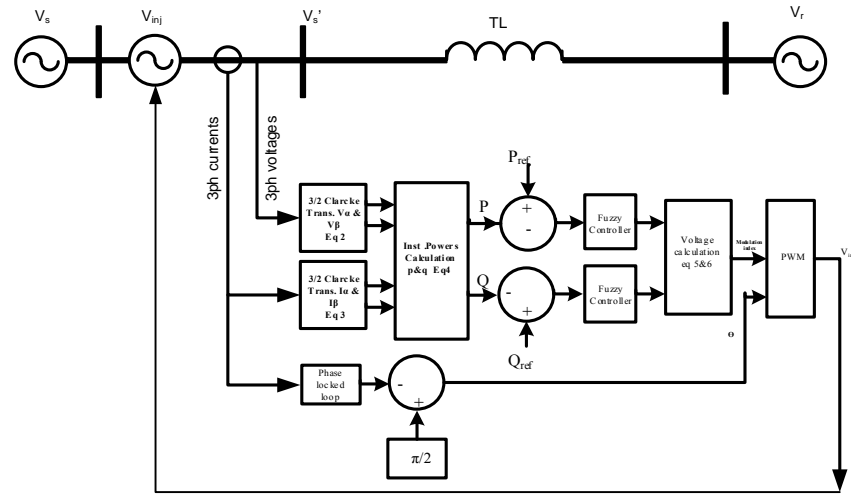

Fig 2 Block diagram for the SSSC control system

Where $i_{\alpha}$ and $i_{\beta}$ are the two-orthogonal components of the current and $v_{\alpha}$ and $v_{\beta}$ are the two-orthogonal components of the voltage. The compensated voltage is:

$$
\left[\begin{array}{l}
v_{\alpha} \\
v_{\beta}
\end{array}\right]=\frac{1}{v_{\alpha}^{2}+v_{\beta}^{g}}\left[\begin{array}{ll}
v_{\alpha} & v_{\beta} \\
v_{\beta}-v_{\alpha}
\end{array}\right]\left[\begin{array}{l}
P \\
q
\end{array}\right]
$$

Where $\mathrm{v}_{\alpha}$ and $\mathrm{v}_{\beta}$ are the quadrature components voltage $\mathrm{p}$ and $\mathrm{q}$ the compensated active and reactive power respectively, the aggregated voltage is :

$v=\sqrt{v_{\alpha}^{2}+v_{\rho}^{2}}$

\section{Control Scheme of SSSC}

The basic control system of the SSSC is shown in Fig.2. The system consists of two generating machines along with transmission line and load. The compensator is provided with a DC voltage source which helps in feeding or absorbing the active and reactive power from the system. For the control circuit as shown, the line voltage and current are sensed and from that measurement active power $\mathrm{P}$ and reactive power $\mathrm{Q}$ are calculated using Clarck's transformations. The desired active and reactive power $\mathrm{P}_{\text {ref }}$ and $\mathrm{Q}_{\text {ref }}$ are compared with the $P$ and $Q$ respectively to generate error signals $E_{p}$ and $E_{q}$. These error signals are processed in the controller where:

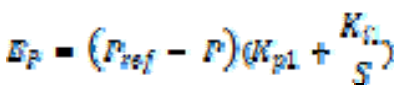

$$
\begin{aligned}
& E_{Q}=\left(Q_{r s i}-Q\right)\left(K_{p 2}+\frac{K_{i q}}{S}\right)
\end{aligned}
$$

\section{ANFIS Based Control System}

Fuzzy systems are suitable for uncertain or approximate reasoning, especially for the system with mathematical model that is difficult to derive. Fuzzy logic controllers play an important role in many practical applications. There are many fuzzy inference mechanisms in fuzzy logic control system from which Takagi-Sugeno is chosen in this study. The Artificial Neural Network (ANN) will be used in this study to tune the membership functions of the TS fuzz-like-PI controller.

The general TS rule structure for two inputs single output system is given as:
Rule $\mathrm{i}$ : if $\mathrm{x}$ is $\mathrm{A}$ and $\mathrm{y}$ is $\mathrm{B}$ then $\mathrm{f}_{\mathrm{i}}=\mathrm{f}(\mathrm{x}, \mathrm{y})$

It provides a simple structure defuzzification process, reduces the overall computation time and offers a wide range of control gain variation based on its variable rule consequent.

However, there are no standard methods for transforming human knowledge into the rule-base of the fuzzy inference system. Hence, the selection of the size, type and parameters of the input and output membership functions are often determined depending on the designer experience or by trial and error. There is a need for effective methods of tuning the membership functions and reducing the rule base to the minimum essential rules. Where, $A_{i}$ and $B_{i}$ represent the linguistic variables of the corresponding input membership functions (MF). $\quad f_{i}$ is the output represented as a function of the system variables, it could have different structure e.g.

$f_{i}=\mathrm{c}($ zero-order TS model $)$

$f_{i}=g_{i} x+h_{i} y+r_{i}$ (first-order TS model)

The coefficients $\left(\mathrm{c}, g_{i} h_{i}\right.$, and $r_{i}$ ) represent the milestone of the TS fuzzy control system design, that is shown in Fig. 3. It produces wide variations of the controller gain. Arbitrary selection of these parameters may lead to an adequate system response or instability [15].

A better system response may be achieved by using NeuroFuzzy system to adapt the fuzzy system parameters and rules by employing ANN learning algorithm. The adaptive TS fuzzy controller used in this work consists of seven triangle membership functions as shown in Fig. 4. Adaptive Neuro-Fuzzy Inference System (ANFIS) was proposed to overcome the above difficulties. Since it combines the fuzzy qualitative approach with the adaptive learning capabilities of the neural network, such a system can be trained without a great amount of expert knowledge usually required for the standard fuzzy logic [10].

As a result, the rule-base can be reduced. A typical architecture of ANFIS based on the first order TakagiSugeno model is shown in Fig. 5, with two-inputs $(\mathrm{x}, \mathrm{y})$ and one-output (f). The architecture is expanded as follows:

Rule ij:if $x$ is $A_{i}$ and $y$ is $B_{j}$ then $f_{i j}=g_{i j} x+h_{i j} y+r_{i j}$

Where, $A i$ and $B j$ represent the input membership functions (MF). $g_{i j}, h_{i j}$ and $r_{i j}$ are the parameters of the output membership functions. The parameters of the input and output membership functions are to be determined during the training stage. ANFIS consists of five layers, each layer has either fixed nodes (that have no parameters to be tuned) represented by a circle or adaptive nodes (that have parameters to be tuned during training) represented by a square, as shown in Fig. 5.a. The output of the five layers which emulate the fuzzy system design steps is given as follows, referring to [16] for more details. 


$$
\begin{aligned}
& O_{1 i}=\mu_{A_{i}}(x) \text { or } O_{1 j}=\mu_{B_{j}}(y) \\
& \begin{array}{l}
O_{2 i j}=w_{i j}=\mu_{A_{i}}(x) \mu_{B_{j}}(y), \\
i=1,2, \ldots N, \quad j=1,2, \ldots M
\end{array} \\
& O_{3 i j}=\bar{w}_{i j}=\frac{w_{i j}}{\sum_{\forall i} w_{i j}} \\
& \begin{array}{c}
O_{4 i j}=\bar{w}_{i j} f_{i j}=\bar{w}_{i j}\left(g_{i j} x+h_{i j} y+r_{i j}\right), \\
i=1,2, \ldots N, \quad j=1,2, \ldots M
\end{array} \\
& O_{5}=f=\sum_{\forall i, j} \bar{w}_{i j} f_{i j}=\sum_{\forall i, j} \frac{w_{i j} f_{i j}}{\sum_{\forall i, j} w_{i j}}=\frac{\sum_{\forall i, j} w_{i j} f_{i j}}{\sum_{\forall i, j} w_{i j}}
\end{aligned}
$$

The objective of the learning algorithm is to adjust the parameters of the input and output membership functions so that the ANFIS output best matching the training data. A hybrid learning strategy (Gradient Descent-GD and Least Squares Estimate-LSE) is applied to identify the network parameters. The GD method updates the antecedent membership function parameters $\left(A_{i}, B_{i}\right)$ while LSE identifies the consequent parameters $\left(g_{i j}, h_{i j}, r_{i j}\right)$. To tune the TS rules using ANFIS, two sets of data are to be generated.

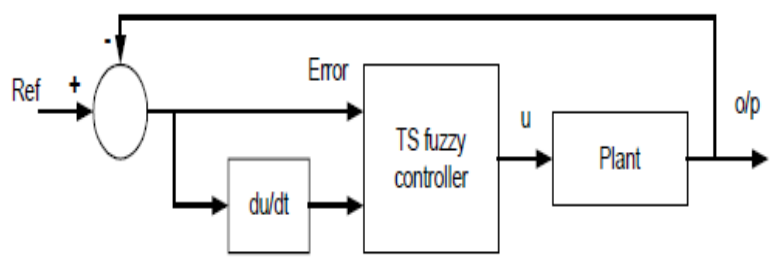

Fig. 3 TS fuzzy control scheme

The input data is a vector of the error and change of error of the active and reactive power flow of the transmission system controlled parameters. The input universe of discourse is split into 7 triangular membership function with 50\% overlapping. Therefore, for two inputs, 49control rule consequent linear functions need to be determined. To initialise the coefficients of the consequents, the data extracted from the standard Mamdani fuzzy like PI controller as described in Table 1 is used to start the training procedure and the error and change of error relation with the output surface shown in Fig. 6. This procedure is performed using the ANFIS included in the MATLAB/FUZZY Logic Toolbox.

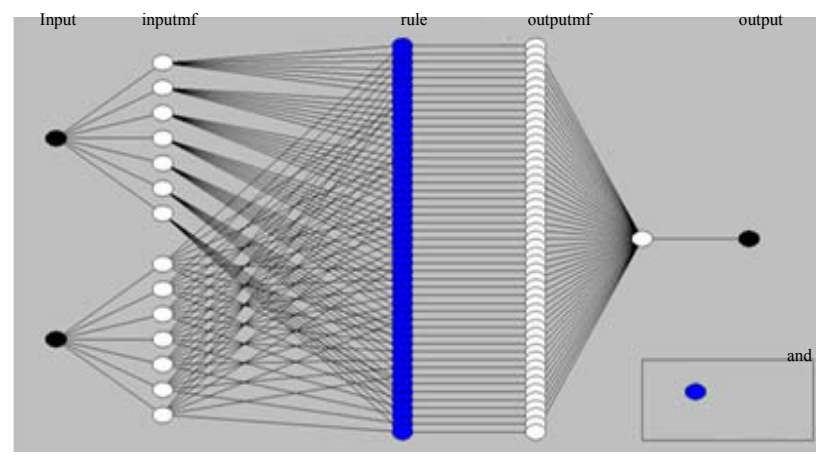

Fig. 4 the ANFIS model structure

\begin{tabular}{|c|c|c|c|c|c|c|c|c|}
\hline \multirow{2}{*}{$\mathrm{Er}$} & \multirow[t]{2}{*}{ Cer } & $\mathrm{NB}$ & $\mathrm{NM}$ & $\mathrm{NS}$ & $\mathrm{ZE}$ & $\mathrm{PS}$ & $\mathrm{PM}$ & $\mathrm{PB}$ \\
\hline & & -1 & $-2 / 3$ & $-1 / 3$ & 0 & $1 / 3$ & $2 / 3$ & 1 \\
\hline NB & -1 & -1 & -1 & -1 & -1 & $-2 / 3$ & $-1 / 3$ & 0 \\
\hline $\mathrm{NM}$ & $-2 / 3$ & -1 & -1 & -1 & $-2 / 3$ & $-1 / 3$ & 0 & $1 / 3$ \\
\hline $\mathrm{NS}$ & $-1 / 3$ & -1 & -1 & $-2 / 3$ & $-1 / 3$ & 0 & $1 / 3$ & $2 / 3$ \\
\hline $\mathrm{ZE}$ & 0 & -1 & -1 & $-1 / 3$ & 0 & $1 / 3$ & $2 / 3$ & 1 \\
\hline PS & $1 / 3$ & -1 & -1 & 0 & $1 / 3$ & $2 / 3$ & 1 & 1 \\
\hline $\mathrm{PM}$ & $2 / 3$ & -1 & 0 & $1 / 3$ & $2 / 3$ & 1 & 1 & 1 \\
\hline PB & 1 & 0 & $1 / 3$ & $2 / 3$ & 1 & 1 & 1 & 1 \\
\hline
\end{tabular}

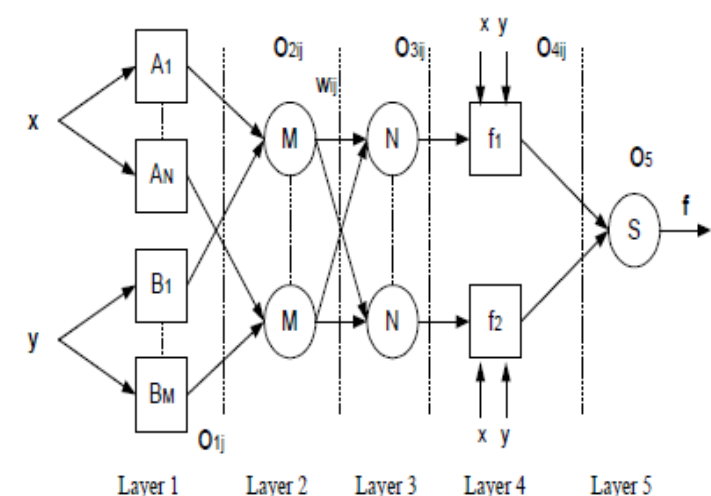

(a)

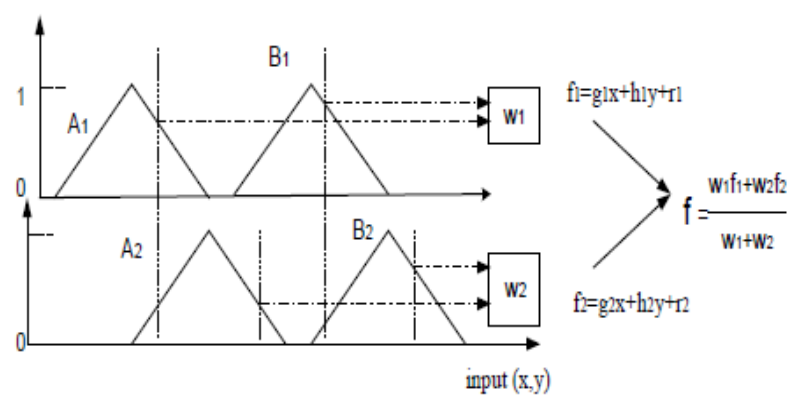

(b)

Fig 5 a-ANFIS structure b-Takagi-Sugeno fuzzy inference

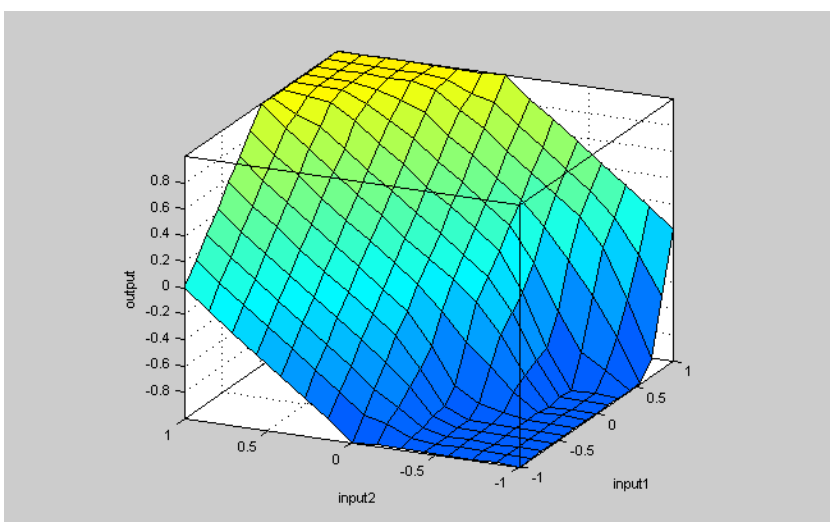

Fig. 6 Control surface of SSSC-based neuro-fuzzy controller

\section{Simulation Study}

The system shown in Fig. 2 is simulated to investigate the performance of the proposed intelligent controller under the step change of the power flow condition. The results 
illustrate clearly the capability of the SSSC to control the real power flow. A PI controller is used for the sake of comparison. In this work, the SSSC is simulated as controlled voltage source. The response to step changes in the system reference signals is used to test the controller performance.

Fig. 7 shows the injected voltage in quadrature with the line current, the amplitude changed depends on the control signals which are the changes in active $\&$ reactive power. Fig. 8 shows the system response to a step change in the real power. From the results it is clear that the ANFISbased controller has a smoother response and reaches the steady state faster than the conventional PI controller. However, both controllers suffer from overshot which yet within the acceptable range of $25 \%$.

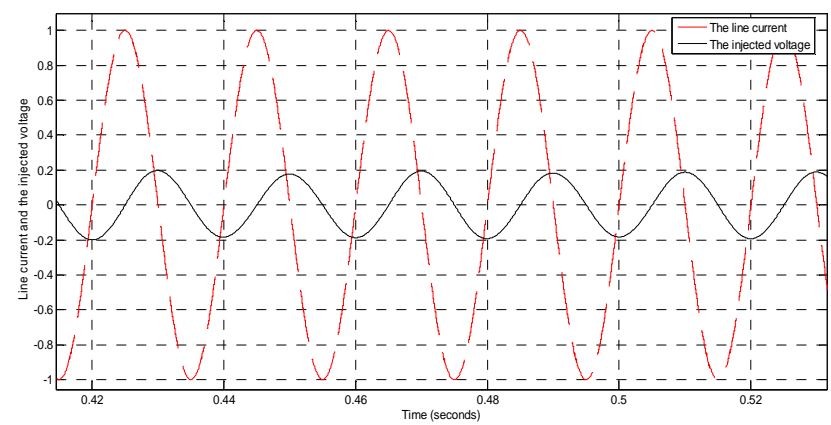

Fig. 7 The line current and the injected voltage

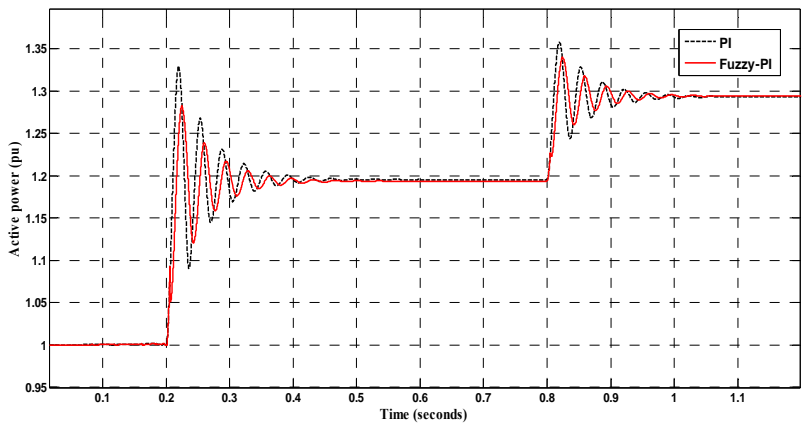

Fig. 8 The step change response for two types controllers

\section{Experimental Results}

The lab model used in this study includes, the host computer that was interfaced with the SSSC and transmission system hardware through the Control Desk software and dSPACE ds1103 data acquisition board. The controller algorithm is developed in the SIMULINK platform then downloaded to the ds 1103 board. A 6-pulse PWM converter connected to the a.c. system through an appropriate transformer with the suitable turns' ratio. The switching frequency of the converter is set to 9 times the system frequency in order to eliminate both the evens and tripled harmonics. A phase shifting transformer, which consists of three phase transformer and three-phase Variac is employed to introduce a phase difference between sending and receiving end voltages of the transmission line, respectively. The phase shifting transformer injects a $90^{\circ}$ voltage with respect to the corresponding sending phase voltage. In this study, the transmission angle was set to $20^{\circ}$ in order to produce sufficient active and reactive power flow suitable for the lab test. Fig. 9 shows the injected voltage quadrature with line current.
To suite the real time implementation of the Fuzzy based TS controller, a step size of $1 /(9 * 64 * 50)$ is chosen to be the sampling period of the digital controllers. This is chosen to avoid asynchronisation of the generated PWM with respect to the fundamental reference. The controller algorithm is designed using 7 membership functions for each input. The three-phase PWM generator of the slave DSP on the main board generates the PWM for the series inverter.

To control the power flow the SSSC inject voltage quadrature with line current (lagging the line current by $90^{\circ}$ ) and control the magnitude. Fig.9 shows the SSSC Capability to regulate the load voltage due to any load variations.

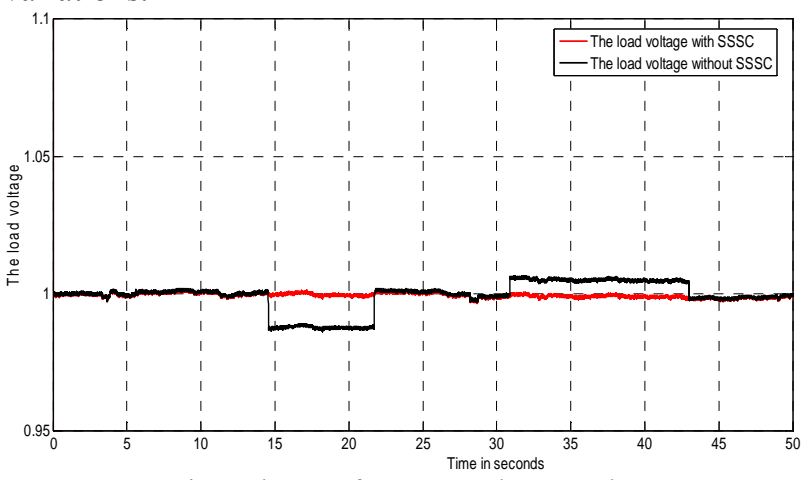

Fig. 9 The use of SSSC as voltage regulator

The active power flow response for two types of controllers PI and Fuzzy-TS is shown in Fig. 10- a \& b. It is clear that the system more stable and faster to reach the steady state. Fig. 11 shows the prototype in the lab.

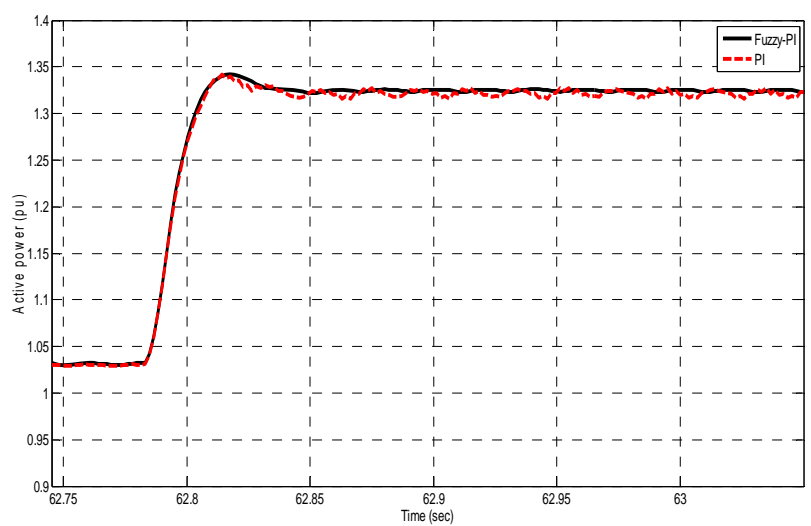

(a)

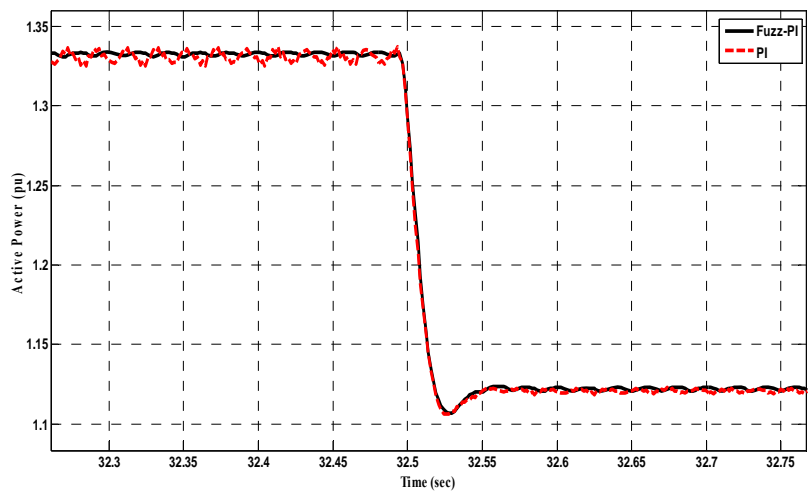

(b)

Fig. 10 a- System response to step change b-The zooming to the step change 


\section{Conclusion}

In this paper, Takagi-Sugeno fuzzy control system algorithm is used to control the SSSC. The tuning algorithm is performed off-line employing the concept of Adaptive Neuro-Fuzzy Inference System (ANFIS). The rules defined by Mamdani fuzzy-like-PI controller are used to initiate the tuning process. The small computation time of the controller has the potential of implementation in real time. The proposed controller has been applied successfully to control the power flow in transmission system.

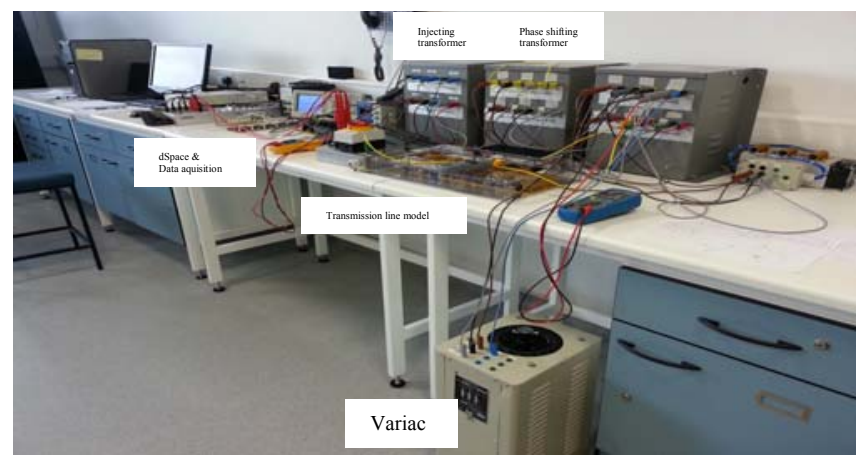

Fig. 11 the the prototype in the lab

The simulation and experimental results show that the proposed controller can provide an adequate performance for the SSSC operation. Also the use of instantaneous power theory gave a fast measurement tool for measuring the active and reactive power.

\section{ACKNOWLEDGMENT}

The author would like to thank the the Iraq government in funding the research. The practical test has been conducted in the Smart Energy Laboratory, School of Engineering \& Built Environment, Glasgow Caledonian University, Glasgow, UK.

\section{References}

[1] L. Gyugyi, "Dynamic compensation of ac transmission lines by solidstate synchronous voltage sources", IEEE Trans. Power Delv., vol. 9, no., pp. 904-911, 1994.

[2] L. Gyugyi, C. D. Schauder, and K. K. Sen, "Static synchronous series compensator: a solid state approach to the series compensation of transmission lines", IEEE Trans. Power Delv., vol. 12, pp. 406-417, 1997.

[3] Swasti Khuntia "Simulation Study of a SSSC-based NeuroFuzzy Controller for Improvement of Transient Stability in a Three-Machine Power System", IEEE energy tech,May 29-31,Ohio, 2012

[4] S. Panda, and N. P. Padhy, "Comparison of particle swarm optimization and genetic algorithm for FACTS-based controller design", Appl. SoftComput., vol.8, no.4, pp. 1418-1427, 2008.

[5] S. Panda, N. P. Padhy and R. N. Patel, "Power system stability improvement by PSO optimized SSSC-based damping controller", Electr. Power Comp. Syst., vol. 36, no.5, pp. 468-490, 2008.

[6] M. A. Abido, "Analysis and assessment of STATCOMbased damping stabilizers for power system stability enhancement", Electr. Power Syst. Research, vol. 73, no. 2, pp. 177-185, Feb. 2005.
[7] S. Panda, "Differential evolutionary algorithm for TCSCbased controller design", Simulat. Model. Pract. Theory, vol. 17, no. 10, pp. 1618-1634, 2009.

[8] Chintan R Patel, Sanjay N Patel," Static Synchronous Series Compensator (SSSC): An approach for reactive power compensation for the transmission system", National Conference on Recent Trends in Engineering \& Technology, B.V.M. Engg College, .V.Nagar, Gujarat, India, 13-14 May 2011.

[9] S. Panda, and N. P. Padhy, "Comparison of particle swarm optimization and genetic algorithm for FACTS-based controller design", Appl. Soft Comput., vol.8, no.4, pp. 1418-1427, 2008.

[10] Chintan R Patel and Sanjay N Patel," Static Synchronous Series Compensator(SSSC): An approach for reactive power compensation for the transmission system", National Conference on Recent Trends in Engineering \& Technology, 13-14 May 2011

[11] S. Panda, "Differential evolutionary algorithm for TCSCbased controller design", Simulat. Model. Pract. Theory, vol. 17, no. 10, pp. 1618-1634, 2009.

[12] S. Panda, "Multi-objective evolutionary algorithm for SSSC-based controller design", Electr. Power Syst. Res.,vol.79, no. 6, pp. 937-944, 2009.

[13] E H Watanabe and Akagi H, "Instantaneous $\mathrm{p}-\mathrm{q}$ power theory for control of compensators in micro-grids" IEEE No sinusoidal Currents and Compensation (ISNCC), 2010 Pages 17-26.

[14] Mohammed Y. Suliman and S. M. Bashi," Instantaneous Active and Reactive Power Measuring in Three Phase Power System", 3rd International Scientific Conference of F.T.E,Najaf,Iraq,20-21 Feb 2013, Page(s): 926-936.

[15] Farrag M. E. A, G. A. Putrus," Design of adaptive neurofuzzy inference controller for a transmission system incorporating UPFC", IEEE, Transaction on Power Delivery, Jan. 2012, Volume:27,Issues:1, pp53-61

[16] Farrag M. E. A., Putrus G. A. and Ran L., "Artificial Neural Network Based Adaptive Takagi-Sugeno Fuzzy Like PI Controller For Optimal UPFC Performance" IEEE 7th International Conference on Intelligent Engineering Systems, Assiut, Egypt 4-6 March 2003, pp. 312-316. 